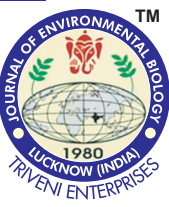

\title{
Phytofabrication of silver nanoparticles using Annona reticulata and assessment of insecticidal and bactericidal activities
}

\begin{tabular}{lll}
\hline Paper received: 29.05.2018 & Revised received: 07.12.2018 & Re-revised received: 17.02 .2019 \\
\hline
\end{tabular}

\section{Authors Info \\ S. Malathi', G. Rameshkumar', R.L. Rengarajan ${ }^{3}$, T. Rajagopal, S. Muniasamy ${ }^{5}$ and P. Ponmanickam ${ }^{6 *}$ \\ 'Department of Botany, \\ Ayya Nadar Janaki Ammal College (Autonomous), Sivakasi-626 124, India 'Department of Zoology, V. H. N., Senthikumara Nadar College (Autonomous), Virudhunagar-626 001, India \\ ${ }^{3}$ Department of Animal Science, Bharathidasan University, Tiruchirappalli-620 024, India ${ }^{4}$ Department of Zoology, Thiagarajar College (Autonomous), Madurai- 625009 , India \\ ${ }^{5}$ Department of Microbiology, Ayya Nadar Janaki Ammal College (Autonomous), Sivakasi-626 124, India \\ ${ }^{6}$ Department of Zoology, Ayya Nadar Janaki Ammal College (Autonomous), Sivakasi-626 124, India \\ *Corresponding Author Email : pon_manick@yahoo.co.in}

\section{Edited by \\ Dr. Bivin Thomas}

Reviewed by

Dr. Sajid Khan

Dr. Alka Srivastava

\section{Abstract}

Aim : Silver nanoparticle synthesis using plant products is now popular due to its environment friendly, easy availability, simple procedure and fascinating properties. In this study, an attempt was made on leaf extract of Annona reticulata $\mathrm{L}$ silver nanoparticles to synthesize and to assess its bactericidal and insecticidal properties.

\begin{abstract}
Methodology : Using plant material for silver nanoparticle synthesis is one of the bottom up approaches of silver nanoparticle synthesis. In the present study leaf extract of Annona reticulata was used for nanoparticle synthesis. The synthesized nanoparticles were characterized by X-Ray Diffraction (XRD), Scanning Electron Microscopy (SEM), Fourier-transform infrared spectroscopy (FTIR) and Energy Dispersive X-Ray Analysis (EDAX). The bactericidal property was evaluated against $E$. coli, $P$. aeruginosa, $S$. aureus, $B$. subtilis and $P$. vulgaris where as insecticidal property was tested against mosquito larvae and Sitophilus oryzae.
\end{abstract}

Results : The XRD spectrum confirmed the formation of silver nanoparticles. SEM observation showed that nanoparticles were $17.33 \mathrm{~nm}$ in size and spherical in shape. The EDAX result revealed the presence of silver in the suspension. Silver nanoparticles exhibited higher repellency against Sitophilus oryzae. and feeding deterrence. The nanoparticles possessed a strong larvicidal activity when they were used against fourth instar larvae of mosquitoes. The silver nanoparticles showed bactericidal activity against Pseudomonas aeruginosa, Proteus vulgaris, Bacillus subtilis, Staphylococcus aureus and Escherichia coli.

Interpretation : The present study strongly suggests that Annona reticulata leaf extract can be used to fabricate silver nanoparticles with potent insecticidal and bactericidal properties.

Key words: Annona reticulata, Antibacterial activity, Insecticidal activity, Phytofabrication, Silver nanoparticles

How to cite : Malathi, S., G. Rameshkumar, R.L. Rengarajan, T. Rajagopal, S. Muniasamy and P. Ponmanickam: Phytofabrication of silver nanoparticles using Annona reticulata and assessment of insecticidal and bactericidal activities. J. Environ. Biol., 40, 626-633 (2019). 


\section{Introduction}

The unique properties of metallic nanoparticles have drawn the attention of many researchers to work on them in comparison to bulk materials. Fabrication of nanoparticles can be done using two approaches top-down and bottom-up. The top-down approach involves synthesis of nanoparticles from bulk material and has a limitation in the form of improper surface nature of nanoparticles and high cost (Thakkar et al., 2010; Mittal et al., 2013). The chemical and biological methods of synthesis belong to the bottom-up approach. In these methods the possibility of getting uniform particle size is high but the chemical mediated synthesis can cause toxicity to health and environment (Aziz and Jassim, 2018). Hence, the biological mode of synthesis is the most preferred method in these days.

Biological method can be microorganism mediated synthesis or plant mediated; out of which, the former is not preferred due to the possibilities of biohazards and the extra step of culture of microorganisms, besides being expensive (Rajagopal et al., 2015). The advantages of using plants for the synthesis of silver nanoparticles are that they are readily available, show vast diversity, are safe to handle and have various metabolites that may be involved in reduction. Moreover, the plant mediated synthesis is an advance of bioscience in a sense that it is high yielding, involves low cost technology and is non-toxic to vertebrate animals (Chaudhari et al., 2016). Plant materials are considered free of toxins, hence, they can be used in medical fields. It is presumed that synthesized silver nanoparticles have properties of both silver nanoparticles and plant. Hence, plants are considered as "Nature's nanofactory" for nanoparticle synthesis (Jha et al., 2009).

Silver nanoparticles gained much importance over the years due to their remarkable optical, electrical and antimicrobial properties. Silver nanoparticles are considered as good alternative to antibiotics against microorganisms. One gram of silver nanoparticles is known to impart bactericidal properties to hundreds of square meter of substrate material (Thakkar et al., 2010). In addition to this, they have proved effective against wide range of microorganisms, as they prevent the creation of microorganism resistance (Aziz and Jassim, 2018).

Previous studies have reported the synthesis of silver nanoparticles using Annona squamosa and their in-vivo cytotoxic effect (Vivek et al., 2012) and antibacterial activity (Jagtap et al., 2013). Present study reports the phytofabrication of silver nanoparticles using Annona reticulata which is an important medicinal plant that possesses insecticidal and bactericidal properties. It is presumed that the silver nanoparticles fabricated using leaves of this plant may have potent insecticidal and bactericidal properties. Hence, the present study aimed to fabricate silver nanoparticles using leaves of $A$. reticulata, and the efficacy of the same for controlling the stored insect pest, mosquito larva and pathogenic bacteria was evaluated.

\section{Materials and Methods}

Preparation of Annona reticulata L. leaf extract : Custard apple (Annona reticulata L.) leaves were collected from Oothur, Kodaikanal, Tamil Nadu, India. Ten gram of matured leaves (8-9 $\mathrm{cm}$ ) were washed with double distilled water and chopped into 10 $\mathrm{mm}$ in size and air dried at room temperature. The dried chopped leaves were boiled for $15 \mathrm{~min}$ at $60^{\circ} \mathrm{C}$ in $100 \mathrm{ml}$ double distilled water. After boiling, the extract was purified by filtering through Whatman No. 1 filter paper and kept at $4^{\circ} \mathrm{C}$ until use.

Phytofabrication of silver nanoparticles and its characterization: Reaction mixture was prepared by mixing 1 $\mathrm{mM}$ silver nitrate $(90 \mathrm{ml})$ with leaf extract $(10 \mathrm{ml})$ and kept at room temperature in dark condition for reduction. The colour change in the reaction mixture indicated the completion of reduction reaction. The colour change in the reaction mixture was checked periodically. After colour change, the solution was filtered through Whatman No. 1 filter paper and the absorbance was read at 300 to $700 \mathrm{~nm}$ using UV-Visible spectrophotometer. The silver nanoparticle solution was purified by continuous centrifugation (1000 rpm for $10 \mathrm{~min}$ ) and redispersed in double distilled water. The synthesized silver nanoparticles were subjected to Fouriertransform infrared spectroscopy (FTIR), Scanning Electron Microscopy (SEM), Energy-dispersive X-ray spectroscopy (EDAX) and X-ray Diffraction (XRD) analysis for studying functional groups, shape, size and presence of elemental silver, respectively. These analysis were carried out at University Science Instrumentation Centre, Alagappa University, Karaikudi.

Insecticidal activity: Insecticidal activity of silver nanoparticles was assessed in stored insect pest, Sitophilus oryzae. Thirty adult insects were obtained from our laboratory where it was reared from infested rice collected from local market. The insect specimens were identified in the Department of Entomology, Tamil Nadu Agricultural University, Madurai. The toxicity of synthesized nanoparticles against $S$. oryzae was assessed (Subramanyan and Roesli, 2000).

Repellency test: The repellency of synthesized nanoparticles, leaf extract and silver nitrate against $S$. oryzae was assessed by the procedure adopted from Auamcharoen et al. (2012). Briefly, Whatman no 1 filter paper $(9 \mathrm{~cm})$ was divided into two equal halves such as control side and experimental side (treated with synthesized nanoparticles $(100 \mu \mathrm{l})$ / leaf extract $(100 \mu \mathrm{l}) /$ silver nitrate $\left(100 \mu \mathrm{l}\right.$ of $\left.1 \mathrm{mM} \mathrm{AgNO}_{3}\right)$. The control half was not treated. The insects (10 nos) were released on the middle of the paper and the number of insects present in each side of the filter paper at different time intervals was counted ( $1 \mathrm{hr}$ each for five times).

Feeding deterrence activity : Antifeedant activities were evaluated by the method of Mahdi and Rahman (2008) with slight modifications. Five gram of rice impregnated with synthesized nanoparticles $(1 \mathrm{ml})$, leaf extract $(1 \%)$ and silver nitrate $(1 \mathrm{mM}$ $\mathrm{AgNO}_{3}$ ) were placed in separate boxes. Then, 10 adult S. oryzae were allowed to feed for 7 days. After feeding period, grains were weighed and weight loss was measured. 
Histopathological findings of Sitophilus oryzae after exposure to silver nanoparticles: The silver nanoparticle treated adult Sitophilus oryzae after death were subjected to routine histological analysis. The dead insects were fixed in alcoholic Bouin's solution for $24 \mathrm{hrs}$. Each insect was subjected to microtechnique through serial dilution, infiltration, embedding and staining following standard procedure (Humason, 1979).

Larvicidal activity: The mosquito larvae ( $4^{\text {th }}$ instar) of Aedes aegypti (10 for each concentration) and Culex quinquefasciatus (10 for each concentration) were placed in $100 \mathrm{ml}$ of water containing various concentrations (10 ppm, 20 ppm, 30 ppm, 40 ppm and 50 ppm ) of silver nanoparticles. Sterile water without nanoparticles and leaf extract served as control (Gnanadesigan et al., 2011).

Histopathology of mosquito larvae after exposure to silver nanoparticles: Histopathological observations of the effects of synthesized silver nanoparticles were conducted on fourth instar larvae of Aedes aegypti and Culex quinquefasciatus. Larvae treated with synthesized silver nanoparticles, leaf extract and $\mathrm{AgNO}_{3}$ and untreated larvae were fixed, dehydrated and mounted in paraffin blocks. Sections of $8 \mu \mathrm{m}$ thickness of larval tissue were made, mounted on glass slides and stained with haematoxylin and eosin for histopathological examination under light microscope.

Bactericidal activity : Agar diffusion assay was used to determine the antibacterial activity of nanoparticles against pathogenic microorganisms like Escherichia coli, Pseudomonas aeruginosa, Staphylococcus aureus, Bacillus subtilis and Proteus vulgaris.

Statistical analysis: The data presented in tables of repellency test, feeding deterrence activity and antibacterial activity are mean $\pm S E$. Data corresponding to the performance of larvicidal effect of AgNPs were subjected to analysis of variance and
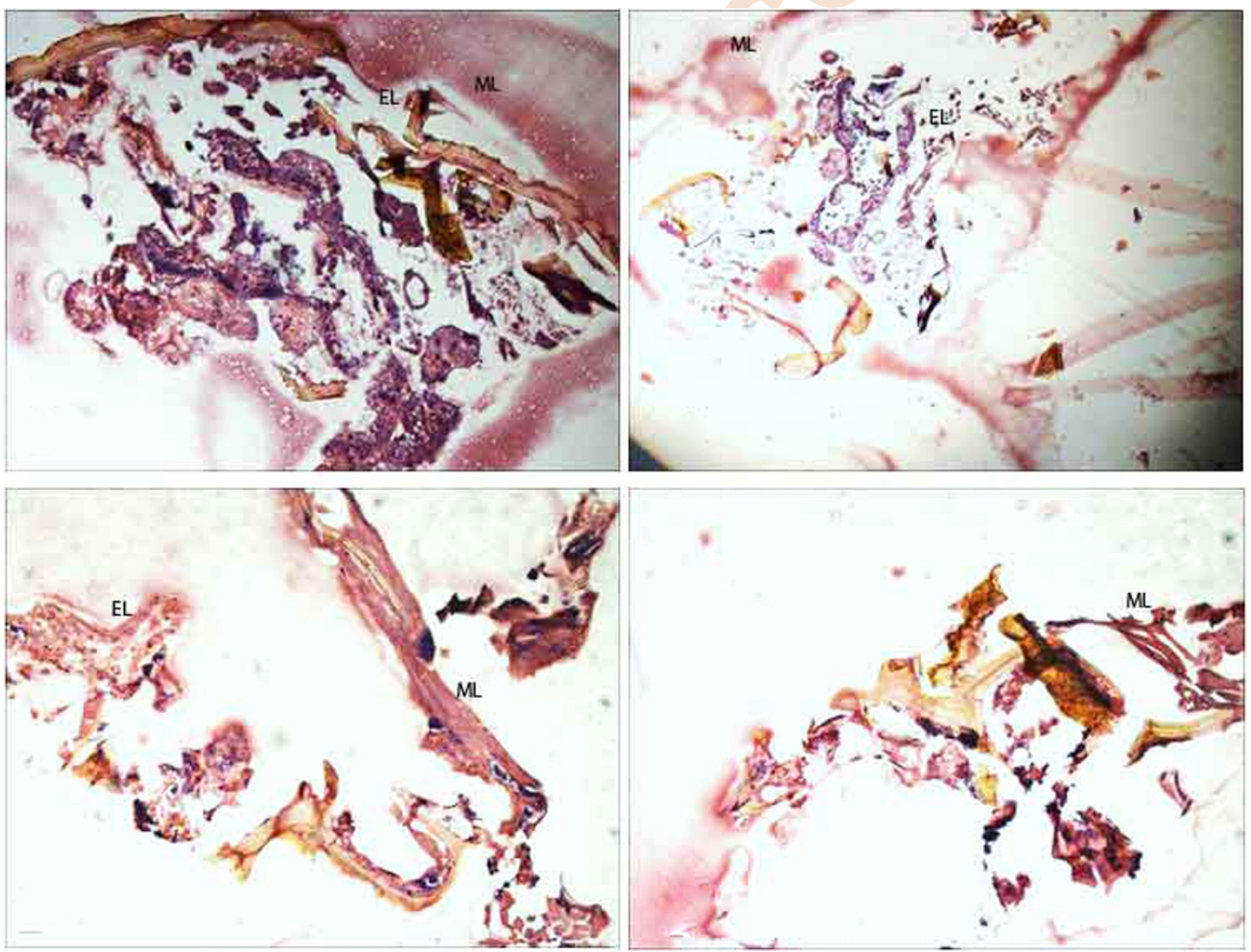

Fig. 1 : Histological sections of Sitophilus oryzae after exposure to silver nanoparticles, A. reticulata leaf extract and $\mathrm{AgNO}_{3}$ : (A) Control; (B) silver nitrate; (C) leaf extract and (D) synthesized silver nanoparticles; (EL-Epithelial layer; ML- Membrane layer). 

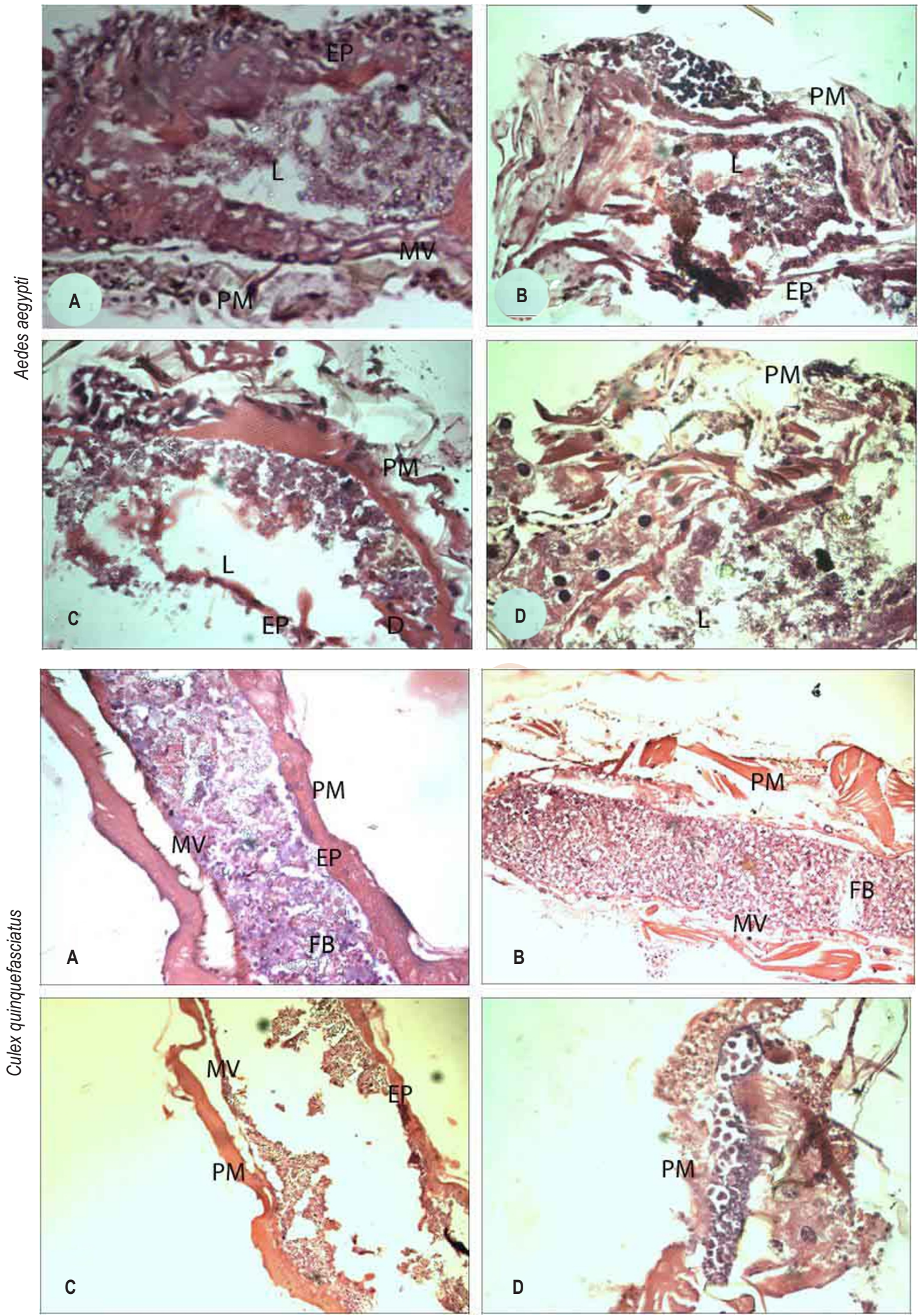

Fig. 2 : Histological sections of $4^{\text {th }}$ instar larvae of Aedes aegypti and Culex quinquefasciatus; after exposure to silver nanoparticles, leaf extract and $\mathrm{AgNO}_{3}$ : (A) Control; (B) Silver nitrate treated; (C) A. reticulata leaf extract treated and (D) Synthesized silver nanoparticle treated (EP-Epithelial cells; PM-Peritrophic matrix; L-Lumen; MV-Microvilli). 
Table 1: Repellency (\%) of synthesized silver nanoparticles (Ag NPs), leaf extract and silver nitrate $\left(\mathrm{Ag} \mathrm{NO}_{3}\right)$ against Sitophilus oryzae adults

\begin{tabular}{llllll}
\hline & \multicolumn{4}{c}{ Duration of exposure } \\
\cline { 2 - 6 } Concentration of samples $\left(\mathbf{1 0 0} \boldsymbol{\mu} \mathbf{~ c m}^{-2}\right)$ & $\mathbf{1 ~ h r}$ & $\mathbf{2 ~ h r}$ & $\mathbf{3 ~ h r}$ & $\mathbf{4} \mathbf{~ h r}$ & $\mathbf{5 ~ h r}$ \\
\hline Control $+\mathrm{AgNO}_{3}$ & 10 & 30 & 30 & 40 & 50 \\
Control + Silver nanoparticles & 30 & 40 & 50 & 80 & 90 \\
Control + leaf extract & 20 & 20 & 30 & 40 & 60 \\
\hline
\end{tabular}

Temperature $=24 \pm 1^{\circ} \mathrm{C}$; Relative humidity $=65-70 \% ; 16 \mathrm{~L}: 8 \mathrm{D}$ photoperiod. The values are $\%$ repellency

average mortality data was calculated $\mathrm{LC}_{50}, \mathrm{LC}_{90}$ lower confidence limit and upper confidence limit values at $95 \%$ using EPA Probit analysis program (version 1.5). $P<0.05$ was considered as significantly different for all statistical tests.

\section{Results and Discussion}

Silver nanoparticle synthesis in reaction mixture was easily predicted initially by visible observation. In the present study, the colour change (watery to yellowish brown) occurred in the reaction mixture after $24 \mathrm{hrs}$. It indicates the reduction of silver ions in the reaction mixture and possible silver nanoparticle synthesis. It is well known that excitation of surface plasmon vibrations of silver nanoparticles in solution show yellowish brown colour (Thirumurgan et al., 2010; Mittal et al., 2013).

After colour change in the filtered reaction mixture was detected by UV-Vis spectrophotometer. In the present study, the absorption spectra of the reaction mixture showed absorbance peak at $455 \mathrm{~nm}$ and broadening of peak indicated that the particles were polydispersed. The UV signature at 440 $460 \mathrm{~nm}$ proved the presence of silver nanoparticles in the reaction mixture (Emeka et al., 2014). Similar phenomenon was reported in Argemone mexicana leaf extract that exhibited the broadening peaks in the reaction media with absorbance peak at $440 \mathrm{~nm}$ (Geethalakshmi and Sarad, 2010; Singh et al. 2010). Swamy and Prasad (2012) obtained absorbance peak at 423 $\mathrm{nm}$ when leaf extract of Santalum album was used for silver nanoparticle synthesis.

FTIR spectral analysis revealed the functional groups in the synthesized silver nanoparticles which are responsible for capping and stabilization of silver nanoparticles. The spectrum showed the presence of ten active functional groups in the synthesized silver nanoparticles. The bands appeared at 3438.84 $\mathrm{cm}^{-1}, 2931.45 \mathrm{~cm}^{-1}, 2881.45 \mathrm{~cm}^{-1}, 1741.60 \mathrm{~cm}^{-1}, 1670.24 \mathrm{~cm}^{-1}$, $1454.23 \mathrm{~cm}^{-1}, 1384.79 \mathrm{~cm}^{-1}, 1340.43 \mathrm{~cm}^{-1}, 1080.06 \mathrm{~cm}^{-1}$ and $1043.42 \mathrm{~cm}^{-1}$ corresponding to $\mathrm{N}-\mathrm{H}$ stretching of aliphatic amides, $\mathrm{O}-\mathrm{H}$ stretching of carboxylic acid, $\mathrm{C}-\mathrm{H}$ stretching of alkanes, $\mathrm{C}=\mathrm{O}$ stretching of ketones, $\mathrm{C}-\mathrm{H}$ bond of alkanes, $\mathrm{CH}_{3} \mathrm{C}-\mathrm{H}$ bond of alkanes, C-F, C-O stretching of alcohols, respectively. Similar trend was reported by Tripathi et al. (2013). Silver nanoparticles were synthesized using Ficus panda leaf which revealed the presence of functional groups like alkene, amide, alkane, ester and ether on synthesized nanoparticles. These molecules may surround the synthesized silver nanoparticles and play dual role such as synthesis and stabilization of nanoparticles (Tripathi et al., 2013). The morphology and size of the biosynthesized silver nanoparticles were provided by SEM images. The diameter of synthesized nanoparticles was 15-25 nm. SEM images showed that the silver nanoparticles were synthesized in high density by Annona reticulata leaf extract. The shape of the silver nanoparticles was found to be spherical in nature.

A large peak of silver in the EDAX result confirmed the presence of silver in the suspension. The rest of the peaks may be attributed to the presence of other compounds in the leaf extract. This result is consistent with the earlier reports in which Elettaria cardamomom (Gnana Jobitha et al., 2012) exhibited silver nanoparticles. The XRD pattern of silver nanoparticles revealed different intensity peaks in the whole spectrum of $2 \theta$ values ranging from 0 to $90^{\circ}$. The silver nanoparticles produced in the present experiment were present in the form of nanocrystals as evidenced by the peaks at $2 \theta$ values of $38.40,32.50$ and 28.10 corresponding to the diffraction exhibited from $4-90^{\circ}$ at range of $2 \theta$. The average estimated particle size of the sample was 17.33 $\mathrm{nm}$. The insecticidal activity of synthesized nanoparticles against Sitophilus oryzae was evaluated. In the toxicity assay, the synthesized nanoparticles exhibited higher activity against $S$. oryzae adults tested with rice and without rice than leaf extract and silver nitrate. When the insects with rice grains were treated with silver nanoparticles, 20\% mortality was observed after 24 hrs. It increased to $40 \%$ after 48 hrs at $100 \mu$ l concentration. When the insects were treated with leaf extract and silver nitrate alone at $100 \mu \mathrm{l}$, only $10 \%$ mortality was noticed after $24 \mathrm{hrs}$ and $20 \%$ after $48 \mathrm{hrs}$. When insects without rice grains were treated with silver nanoparticles, $50 \%$ mortality was observed after $24 \mathrm{hrs}$ and $100 \%$ mortality was observed at the concentration of $100 \mu \mathrm{l}$ after $48 \mathrm{hrs}$. When the insects were treated with leaf extract and silver nitrate, $10 \%$ and $30 \%$ mortality were noticed after $24 \mathrm{hrs}$ and $30 \%$ and $50 \%$ mortality were noticed after $48 \mathrm{hrs}$ at the concentration of $100 \mu$ l, respectively. The reports on insecticidal activity of silver nanoparticles are meager. The present study provides the evidence that synthesized nanoparticles exhibited higher toxicity against $S$. oryzae adults when reared without rice than reared with rice. The synthesized silver nanoparticles were repellent to $S$. oryzae (Table 1). The nanoparticles exhibited higher repellency effect against $S$. oryzae than silver nitrate and leaf extract alone. After releasing insects in the test chamber, they 
Table 2 : Larvicidal activity of silver nanoparticles (Ag NPs) synthesized by using Annona reticulata leaf extract against larvae of $A$. aegypti and $C$. quinquefasciatus

\begin{tabular}{|c|c|c|c|c|c|c|c|}
\hline Species & $\begin{array}{l}\text { Concentration } \\
\text { of AgNPs (ppm) }\end{array}$ & $\%$ mortality & $\begin{array}{l}\mathrm{LC}_{50} \\
(\mathrm{ppm})\end{array}$ & $\begin{array}{l}\text { UCL - LCL } \\
(\mathrm{ppm})\end{array}$ & $\begin{array}{l}\mathrm{LC}_{90} \\
(\mathrm{ppm})\end{array}$ & $\begin{array}{l}\text { UCL - LCL } \\
(p p m)\end{array}$ & $x^{2}$ \\
\hline & 10 & $30 \pm 0.745$ & & & & & \\
\hline & 20 & $50 \pm 0.687$ & & & & & \\
\hline \multirow[t]{5}{*}{ Aedes aegypti } & 30 & $60 \pm 0.816$ & 2.38 & $2.66-2.11$ & 2.81 & $3.37-2.24$ & 7.81 \\
\hline & 40 & $80 \pm 0.500$ & & & & & \\
\hline & 50 & $100 \pm 0.000$ & & & & & \\
\hline & 10 & $20 \pm 0.471$ & & & & & \\
\hline & 20 & $30 \pm 0.763$ & & & & & \\
\hline Culex & 30 & $50 \pm 0.105$ & 2.26 & $2.54-1.99$ & 2.81 & $3.23-2.26$ & 7.81 \\
\hline \multirow[t]{2}{*}{ quinquefasciatus } & 40 & $70 \pm 0.745$ & & & & & \\
\hline & 50 & $100 \pm 0.000$ & & & & & \\
\hline
\end{tabular}

UCL: Upper Confidence Limit; LCL: Lower Confidence Limit; Values are mean of replicates \pm S.D.

showed $30-90 \%$ of repellency effect to synthesized silver nanoparticles at 1 to $5 \mathrm{hrs}$. However, this effect was found to be lesser in leaf extract (20-60\%) and silver nitrate (10-50\%). At the end of the experiment ( $5 \mathrm{hrs}$ ), the $100 \mu \mathrm{cm}^{-2}$ concentration of synthesized silver nanoparticles showed strongest repellency effect $(90 \%)$ against S. oryzae.

The feeding deterrence effect was noticed higher in the rice treated with synthesized silver nanoparticles than that of leaf extract and silver nitrate. The study showed the mean weight loss on rice treated with synthesized silver nanoparticles was lower $(0.13 \pm 0.007 \mathrm{~g})$ compared to control $(0.74 \pm 0.030 \mathrm{~g})$, silver nitrate $(0.48 \pm 0.119 \mathrm{~g})$ and leaf extract $(0.31 \pm 0.016 \mathrm{~g})$. Silver nanoparticles induced histological changes in the mid gut of Sitophilus oryzae. They destroyed the membrane and epithelial layer of mid gut (Fig. 1). The degradation of layers was found to be higher with silver nanoparticles than the leaf extract and silver nitrate solution. The studies on histopathological changes in the Sitophilus oryzae treated with silver nanoparticles are meagre. The present study provides the first evidence that histopathological changes in the mid gut of S. oryzae were due to the application of silver nanoparticles.

The maximum (100\%) larvicidal activity was observed at 50 ppm concentration of synthesized silver nanoparticles against fourth instar larvae of $A$. aegypti and $C$. quinquefasciatus (Table 2). The $L C_{50}$ values were determined as 2.38 and $2.26 \mathrm{ppm}$ for $A$. aegypti and $C$. quinquefasciatus whereas the $L C_{90}$ values were found to be 2.81 and $2.81 \mathrm{ppm}$ for $A$. aegypti and $C$. quinquefasciatus respectively (Table 2). These results are in confirmation with the previous study of Sarah et al. (2012) who reported the larvicidal activity of silver nanoparticles against Aedes albopictus larvae. Compared to control (untreated larvae), the mosquito larvae treated with sliver nanoparticles, leaf extract and silver nitrate showed histological changes (Fig.2 a,b). Disorganized cellular architecture was noticed in larvae of both mosquitoes when treated with silver nanoparticles. It is presumed that the larval death is caused due to the penetration of silver nanoparticles in to the larval skin. It is also possible that silver nanoparticles damage some cellular organelles and enzymes

Table 3: Antibacterial activity of synthesized silver nanoparticles (Ag NPs) using aqueous leaf extract of Annona reticulata against bacterial pathogens

\begin{tabular}{|c|c|c|c|c|c|c|c|}
\hline \multirow{3}{*}{$\begin{array}{l}\text { Bacterial } \\
\text { strains }\end{array}$} & \multicolumn{7}{|c|}{ Zone of inhibition (mm) } \\
\hline & \multicolumn{2}{|c|}{ Control } & \multicolumn{5}{|c|}{ Different conc. of synthesized AgNPs } \\
\hline & $\mathrm{AgNO}_{3}(20 \mu \mathrm{l})$ & $\begin{array}{l}\text { Plant extract } \\
(20 \mu \mathrm{l})\end{array}$ & $10 \mu \mathrm{l}$ & $20 \mu \mathrm{l}$ & $30 \mu \mathrm{l}$ & $40 \mu \mathrm{l}$ & $50 \mu \mathrm{l}$ \\
\hline E. coli & $16 \pm 0.353$ & 0 & $12 \pm 0.414$ & $12 \pm 0.353$ & $13 \pm 0.353$ & $13 \pm 0.059$ & $13 \pm 0.250$ \\
\hline P.aeruginosa & $25 \pm 0.790$ & 0 & $13 \pm 0.250$ & $15 \pm 0.239$ & $17 \pm 0.414$ & $17 \pm 0.750$ & $18 \pm 0.790$ \\
\hline S.aureus & 0 & 0 & $10 \pm 0.250$ & $11 \pm 0.216$ & $11 \pm 0.216$ & $13 \pm 0.544$ & $13 \pm 0.612$ \\
\hline B. subtilis & $19 \pm 0.250$ & 0 & $11 \pm 0.250$ & $15 \pm 0.353$ & $15 \pm 0.414$ & $16 \pm 0.353$ & $16 \pm 0.250$ \\
\hline P. vulgaris & 0 & 0 & 0 & 0 & 0 & 0 & 0 \\
\hline
\end{tabular}

Values are mean of replicates \pm S.E. 
(Rai et al. 2009; Rajagopal et al., 2015). The membrane permeability change along with disturbance in proton motive force may also cause loss of cellular function and finally cell death (Sarah et al., 2012). The antibacterial activity assay was carried out on human pathogens like Escherichia coli, Pseudomonas aeruginosa, Staphylococcus aureus, Bacillus subtilis and Proteus vulgaris by standard well diffusion method. Antibacterial efficacy was observed higher in silver nanoparticles than silver nitrate solution and leaf extract alone (Table 3). Bactericidal efficacy at $50 \mu$ l concentration of synthesized silver nanoparticles was more effective against the tested bacterial strains. The highest antibacterial activity was observed against $P$. aeruginosa $(18 \pm 0.790 \mathrm{~mm}$ zone of inhibition) followed by $B$. subtilis $(16 \pm 0.250 \mathrm{~mm})$, E. coli $(13 \pm 0.250 \mathrm{~mm})$ and Staphylococcus aureus $(13 \pm 0.612 \mathrm{~mm})$. However, no activity was noticed against Proteus vulgaris.

At present, there is an urgent need to construct antibacterial drugs from other sources as microorganisms develop resistance against most antibiotics. The present study has proved that the synthesized AgNPs possess potent bactericidal activity. The lethal activity of silver nanoparticles on bacteria is still obscure. It is suggested that silver nanoparticles may bind on the bacterial cell wall, and subsequently enter the cell membrane and alter the membrane permeability leading to cell death (Thakkar et al., 2010; Ramamurthy et al., 2013; Aziz and Jassim, 2018). Seralathan et al. (2014) reported that differential bactericidal activity of silver nanoparticles may be due to the presence of capping agents and stabilizers which are used in the synthesis of silver nanoparticle. It is concluded that the silver nanoparticles synthesized from $A$. reticulata exhibit multiactivities such as insecticidal, repellent, deterrent, larvicidal and bactericidal activities. It would be very helpful to design nanoformulations in pesticide industry as well as in therapeutics.

\section{Acknowledgments}

The authors would like to thank the Management and the Principal, Ayya Nadar Janaki Ammal College (Autonomous), Sivakasi for providing facilities to carry out this research work and for their encouragement.

\section{References}

Auamcharoen, W., A. Chandrapatya, A. Kijjoa and Y. Kainoh: Toxicity and repellency activities of the crude methanol extract of Duabanga grandiflora (Lythraceae) against Sitophilus oryzae (Coleoptera: Curculionidae). Pakistan J. Zool., 44, 227-232 (2012).

Aziz, W.J. and H.A. Jassim: Green chemistry for the preparation of silver nanoparticles using mint leaf leaves extracts and evaluation of their antimicrobial potential. World News Nat. Sci., 18, 163-170 (2018).

Chaudhari, P.S., A. Damahe and P. Kumbhar: Silver nanoparticles-A review with focus on green synthesis. Int. J. .Pharma Res. Rev., 5, 14-28 (2016)

Emeka, E. E., O.C. Ojiefoh, C. Aleruchi, L.A.Hassan, O. M. Christiana, M. Rebecca, E.O. Dare and A.E. Temitope: Evaluation of antibacterial activities of silver nanoparticles green-synthesized using pineapple leaf (Ananas comosus). Micron, 57, 1-5 (2014).

Geethalakshmi, R. and D. V. L. Sarada: Synthesis of plant-mediated silver nanoparticles using Trianthema decandra extract and evaluation of their anti microbial activities. Int. J. Engin. Sci. Technol., 2, 970-975 (2010).

Gnana Jobitha, G., G. Anna durai and C. Kannan: Green synthesis of silver nanoparticle using Elettaria cardamomom and assessment of its antimicrobial activity. Int. J. Pharma. Sci. Res., 3, 323-330 (2012).

Gnanadesigan, M., M. Anand, S. Ravikumar, M. Maruthupandy, V. Vijayakumar, S. Selvam, M. Dhineshkumar and A. K. Kumaraguru: Biosynthesis of silver nanoparticles by using mangrove plant extract and their potential mosquito larvicidal property. Asian Pacific J. Tropical Med., 4, 799-803 (2011).

Humason, G. L.: Animal Tissue Techniques. $4^{\text {th }}$ Edn., W. H. Freeman, San Francisco (1979).

Jagtap, U.B. and V.A. Bapat: Biosynthesis, characterization and antibacterial activity of silver nanoparticles by aqueous Annona squamosa L. leaf extract at room temperature. J. Plant Biochem. Biotechnol., 22, 434-440 (2013).

Jha, A.K., K. Prasad, K. Prasad and A.R. Kulkarni: Plant system: Nature's nanofactory. Colloids and Surfaces B: Biointerfaces, 73, 219-223 (2009).

Keita, S., C. Vincent, J. Schmit, J. Arnason and A. Belanger: Efficacy of essential oil of Ocimum basilicum L. and O. gratissimum L. applied as an insecticidal fumigant and powder to control Callosobruchus maculatus (Fab.) [Coleoptera: Bruchidae]. J. Stored Produc. Res. , 37, 339-349 (2001)

Mahdi, S. and M. Rahman: Insecticidal effect of some spices on Callosobruchus maculatus (Fabricius) in black gram seeds. University J. Zool., 27, 47-50 (2008).

Mittal, A.K., Y, Chisti and U.C. Banerjee: Synthesis of metallic nanoparticles using plant extracts. Biotechnol. Advan., 31, 346-356 (2013).

Rai, M., A. Yadav and A. Gade: Silver nanoparticles as a new generation of antimicrobials. Biotechnol. Advan., 27, 76-83 (2009).

Rajagopal, T., I.A.A. Jemimah, P. Ponmanickam and M. Ayyanar: Synthesis of silver nanoparticles using Catharanthus roseus root extract and its larvicidal effects. J. Environ. Biol., 36, 1283-1289 (2015).

Ramamurthy, C.H., M. Padma, R. Mareeswaran, A. Suyavaran, M.S. Kumar, K. Premkumar and C. Thirunavukkarasu: The extra cellular synthesis of gold and silver nanoparticles and their free radical scavenging and antibacterial properties. Colloids and Surfaces $B$ : Biointerfaces, 102, 808-815(2013).

Sarah, S.J., P. K. Raji, N. Chandramohanakumar and M. Balagopalan: Larvicidal potential of biologically synthesised silver nanoparticles against Aedes albopictus. Res. J. Recent Sci., 1, 52-56 (2012).

Seralathan, J., P. Stevenson, S. Subramaniam, R. Raghavan, B. Pemaiah, A. Sivasubramanian and A. Veerappan: Spectroscopy investigation on chemo-catalytic, free radical scavenging and bactericidal properties of biogenic silver nanoparticles synthesized using Salicornia brachiata aqueous extract. Spectrochimica Acta Part A : Molecular and Biomolecular Spectroscopy, 118, 349-355 (2014).

Singh, A., D. Jain, M.K. Khandelwal and H.N. Verma: Green synthesis of silver nanoparticles using Argemone mexicana leaf extract and evaluation of their antimicrobial activities. Digest. Nanomat. Biostruct., 5, 483-489 (2010).

Subramanyam, B.H. and R. Roesli: Inert dusts. In: Alternatives to pesticides in stored-product IPM (Eds.: B. Subramanyam and D.W. Hagstrum). Kluwer Academic Publishers, Dordreecht, p. 321 (2000). 
Swamy, V.S. and R. Prasad: Green synthesis of silver nanoparticles from the leaf extract of Santalum album and its antimicrobial activity. J. Optoelect. Biomed. Mat., 4, 53-59 (2012).

Thakkar, K.N., S.S. Mhatre and R.Y. Parikh: Biological synthesis of metallic nanoparticles. Nanomedicine: Nanotechnol., Biol. Med., 6. 257-262(2010).

Thirumurgan, A., N.A. Tomy, R.J. Ganesh and S. Gobikrishnan: Biological reduction of silver nanoparticles using plant leaf extracts and its effect an increased antimicrobial activity against clinically isolated organism. DerPhara Chemica, 2, 279-284(2010).

Tripathi, R.M., N. Kumar, A. Shrivastava, P. Singh and B.R. Shrivastav: Catalytic activity of biogenic silver nanoparticles synthesized by Ficus panda leaf extract. J. Molec. Cataly. B: Enzymatic, 96, 7580 (2013)

Vivek, R., R. Thangam, K. Muthuchelian, P. Gunasekaran, K. Kaveri and S. Kannan: Green biosynthesis of silver nanoparticles from Annona squamosa leaf extract and its in vitro cytotoxic effect on MCF-7 cells. Process Biochemistry, 47,2405-2410 (2012). 